\title{
Vessel Dosing Unit
}

National Cancer Institute

\section{Source}

National Cancer Institute. Vessel Dosing Unit. NCl Thesaurus. Code C150017.

A unit of presentation used to represent the quantity of product that is found in a single vessel-type container. 